\title{
Ultraviolet-assisted oiling assessment improves detection of oiled birds experiencing clinical signs of hemolytic anemia after exposure to the Deepwater Horizon oil spill
}

\author{
Jesse A. Fallon (10) ${ }^{1}$ - Eric P. Smith ${ }^{2} \cdot$ Nina Schoch $^{3} \cdot$ James D. Paruk $^{4} \cdot$ Evan M. Adams $^{5} \cdot$ David C. Evers $^{5}$. \\ Patrick G. R. Jodice ${ }^{6} \cdot$ Marie Perkins $^{7} \cdot$ Dustin E. Meattey ${ }^{5} \cdot$ William A. Hopkins $^{1}$
}

Accepted: 11 July 2020 / Published online: 12 August 2020

(c) Springer Science+Business Media, LLC, part of Springer Nature 2020

\begin{abstract}
While large-scale oil spills can cause acute mortality events in birds, there is increasing evidence that sublethal oil exposure can trigger physiological changes that have implications for individual performance and survival. Therefore, improved methods for identifying small amounts of oil on birds are needed. Because ultraviolet (UV) light can be used to identify thin crude oil films in water and on substrate that are not visually apparent under normal lighting conditions, we hypothesized that UV light could be useful for detecting small amounts of oil present on the plumage of birds. We evaluated black skimmers (Rynchops niger), brown pelicans (Pelecanus occidentalis), clapper rails (Rallus crepitans), great egrets (Ardea alba), and seaside sparrows (Ammodramus maritimus) exposed to areas affected by the Deepwater Horizon oil spill in the Gulf of Mexico as well as from reference areas from 20 June, 2010 to 23 February, 2011. When visually assessed without UV light, $19.6 \%$ of birds evaluated from areas affected by the spill were determined to be oiled (previously published data), whereas when examined under UV light, $56.3 \%$ of the same birds were determined to have oil exposure. Of 705 individuals examined in areas potentially impacted by the spill, we found that fluorescence under UV light assessment identified 259 oiled birds that appeared to be oil-free on visual exam, supporting its utility as a simple tool for improving detection of modestly oiled birds in the field. Further, UV assessment revealed an increase in qualitative severity of oiling (approximate $\%$ of body surface oiled) in $40 \%$ of birds compared to what was determined on visual exam. Additionally, black skimmers, brown pelicans, and great egrets exposed to oil as determined using UV light experienced oxidative injury to erythrocytes, had decreased numbers of circulating erythrocytes, and showed evidence of a regenerative hematological response in the form of increased reticulocytes. This evidence of adverse effects was similar to changes identified in birds with oil exposure as determined by visual examination without UV light, and is consistent with hemolytic anemia likely caused by oil exposure. Thus, UV assessment proved useful for enhancing detection of birds exposed to oil, but did not increase detection of birds experiencing clinical signs of anemia compared to standard visual oiling assessment. We conclude that UV light evaluation can help identify oil exposure in many birds that would otherwise be identified visually as unexposed during oil spill events.
\end{abstract}

Keywords Deepwater horizon $\cdot$ Oil spill $\cdot$ Heinz bodies $\cdot$ Ultraviolet fluorescence $\cdot$ Hemolytic anemia

\footnotetext{
Supplementary information The online version of this article (https:// doi.org/10.1007/s10646-020-02255-8) contains supplementary material, which is available to authorized users.

Jesse A. Fallon

jfallon@vt.edu

1 Department of Fish and Wildlife Conservation, Virginia Tech, Blacksburg, VA, USA

2 Department of Statistics, Virginia Tech, Blacksburg, VA, USA

3 Adirondack Center for Loon Conservation, Ray Brook, NY, USA

4 Saint Joseph's College of Maine, Portland, ME, USA

Biodiversity Research Institute, Portland, ME, USA

6 U.S. Geological Survey South Carolina Cooperative Fish and Wildlife Research Unit, Clemson University, Clemson, SC, USA

7 John A. Paulson School of Engineering and Applied Sciences, Harvard University, Cambridge, MA, USA
} 


\section{Introduction}

Acute avian mortality associated with large-scale oil spills is well documented, with seabirds, waterfowl, and colonial waterbirds at particular risk (e.g., Piatt et al. 1990; Iverson and Esler 2010; Munilla et al. 2011; USFWS 2011). However, there is increasing evidence that sublethal exposure (modest external oiling that does not result in rapid mortality) can have important impacts upon individual health and may affect population dynamics, which could influence damage assessments and subsequent restoration and mitigation efforts (Seiser et al. 2000; Trust et al. 2000; Golet et al. 2002; Alonso-Alvarez et al. 2007; Harr et al. 2017; Fallon et al. 2018). Consequently, it is important not only to identify birds that have died from oil exposure, but also to identify birds with sublethal exposure to better estimate the number of birds at risk following both smalland large-scale oil spill events. However, identifying small amounts of oil on feathers can be difficult, especially in birds with dark plumage, under natural lighting conditions. Failure to detect modest oiling may result in inaccurate estimates of the number of birds exposed during oil spills events. Therefore, there is a need for simple, reliable techniques to identify small amounts of oil on birds.

Crude oil fluoresces under ultraviolet (UV) light (Burlamacchi et al. 1983; Colligan and LaManna 1993; Fingas and Brown 2014). This attribute has led to its use to improve detection of oil in several abiotic matrices. For example, UV light can be used to enhance detection of oil on or below the surface of a body of water as well as on snow and ice (Fingas and Brown 2000; Fingas and Brown 2013). Remote UV sensors are commonly used to monitor oil films associated with spills in very thin layers down to $0.1 \mu \mathrm{m}$ (Fingas and Brown 1997; Brekke and Solberg 2005; Jha et al. 2008). Thus, we hypothesized that UV light may also be useful to detect small amounts of oil on the feathers of captured birds that might not be apparent under normal light conditions.

Birds experiencing modest exposure to crude oil can experience myriad physiological effects, including inflammation, immunosuppression, and oxidative damage to cells (Fry et al. 1986; Leighton 1986; Leighton 1995; Briggs et al. 1996; Golet et al. 2002). These sublethal effects can negatively impact growth, alter organ function, reduce reproductive success, and likely increase risk of disease (Briggs et al. 1996; Esler et al. 2000; Giese et al. 2000; Eppley and Rubega 1990; Alonso-Alvarez et al. 2007). Of the sublethal, physiological impacts resulting from avian exposure to oil spills, oxidative damage to erythrocytes and subsequent anemia are of particular interest during oil spill investigations, as such injury can be evaluated in blood samples taken from live birds. Hemolytic anemia has been demonstrated in several species of birds exposed to crude oil under both experimental (e.g., Leighton et al. 1983, 1985; Fry and Lowenstine 1985; Harr et al. 2017) and natural conditions (Yamato et al. 1996; Troisi et al. 2007; Fallon et al. 2018). Although most work has focused on severe oiling, recent evidence indicates that small amounts of visible oiling correlate with oxidative injury to erythrocytes in several species of birds (Fallon et al. 2018).

In this investigation, we evaluated the utility of UV fluorescence as a tool to identify birds with small amounts of oil on their plumage that might otherwise be missed by traditional visual oiling assessment during and in the immediate aftermath of the 2010 Deepwater Horizon oil spill in the Gulf of Mexico, USA. To achieve this objective, we determined the presence and severity of oiling (\% of body surface oiled) by visual inspection under natural light (visual oiling assessment) and then again under UV light (UV oiling assessment) in black skimmers (Rynchops niger, BLSK), brown pelicans (Pelecanus occidentalis, BRPE), great egrets (Ardea alba, GREG), clapper rails (Rallus crepitans, CLRA), and seaside sparrows (Ammodramus maritimus, SESP). Second, we evaluated relationships between severity of visible oiling, UV oiling, and a suite of hematologic parameters characteristic of adverse effects from oil exposure in BLSK, BRPE, and GREG. We evaluated these relationships to determine whether UV oiling assessment improved detection of the number of birds experiencing adverse clinical signs compared to those detected through visual assessment alone.

\section{Methods}

\section{Study area and focal species}

Our five focal species represent a diversity of ecological niches, which could influence their relative susceptibility to oil exposure. Clapper rails and SESP are year-round residents along the Gulf Coast, inhabit salt marshes surrounded by open water, and are omnivorous, eating seeds and marine invertebrates (Post and Greenlaw 2020; Rush et al. 2020). Black skimmers, recognized as a species with declining populations (Vieira et al. 2018), were selected because of their unique surface water foraging strategy and because their nesting habits (sand and shell beaches and islands) put them at high risk for exposure to oil (Gochfeld et al. 2020). Brown pelicans eat mostly fish and are at high risk of dermal exposure to oil because they capture their food most often by diving after prey (Shields 2020). Great egrets forage for food in a wide range of habitats and are unique among the other species evaluated in this study because they are a wading bird that has diverse prey items, including fishes, insects, marine invertebrates, small mammals, reptiles, and amphibians (McCrimmon et al. 2020). 


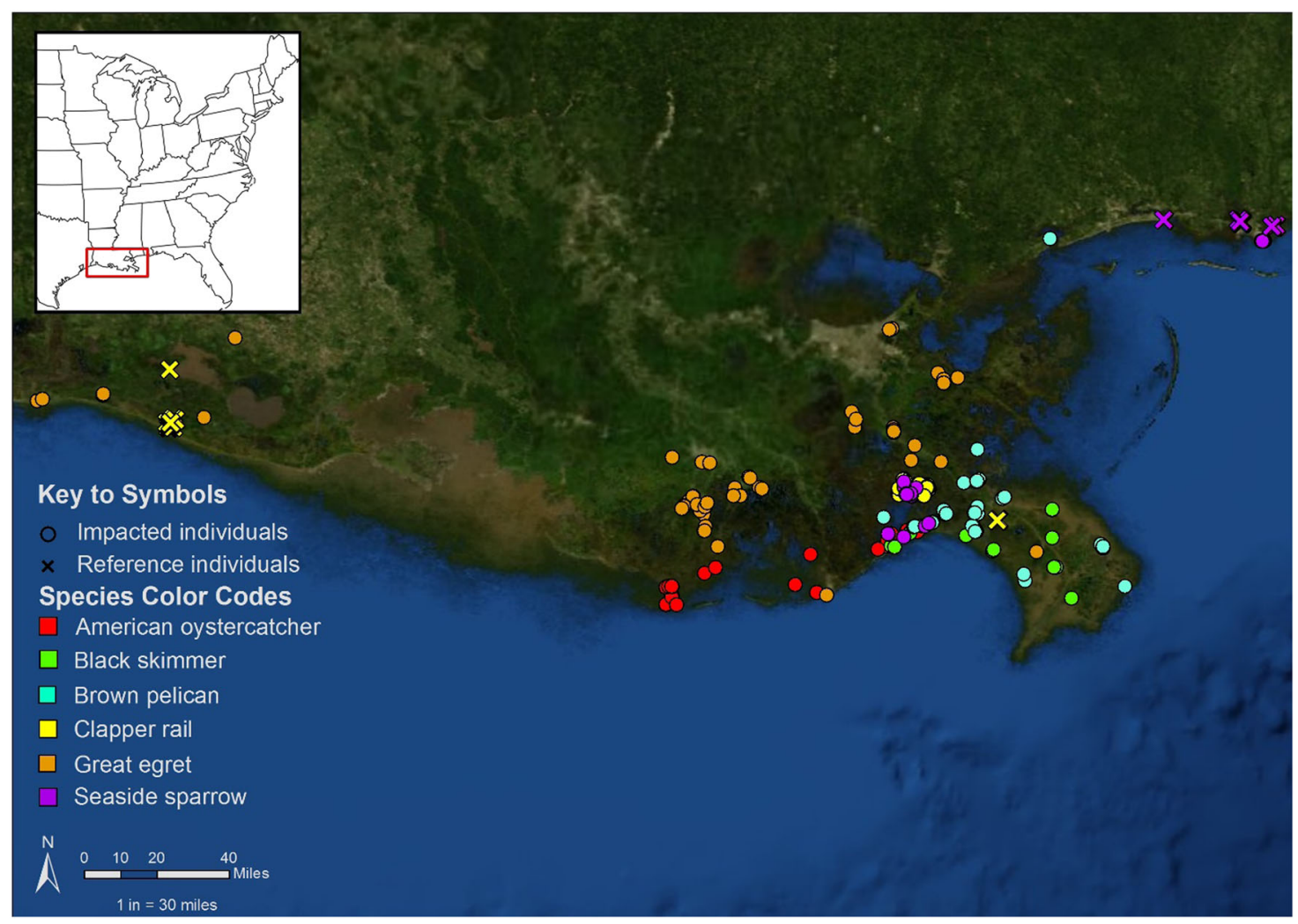

Fig. 1 Area of potential impact capture locations in Louisiana, Mississippi and Alabama for American oystercatcher, black skimmer, brown pelican, and great egret. Also shown are reference capture locations and area of potential impact capture locations for clapper rail

The procedures involving animals were conducted by Biodiversity Research Institute with approval from the US Fish and Wildlife Service. We captured BLSK $(n=120)$, BRPE $(n=66)$, CLRA $(n=100)$, GREG $(n=54)$, and SESP $(n=365)$ from reference areas and areas impacted by the Deepwater Horizon spill from 20 June, 2010 until 23 February, 2011. We captured BLSK with noose mats, box traps, and cannon-nets, BRPE with noose traps, padded leghold traps, and net guns, CLRA by hand with night lighting from airboats as well as with drift fences leading to box traps, GREG with net guns, and SESP with targeted mist netting (Mills and Ryder 1979; Crozier and Gawlik 2003; Herring et al. 2008; Perkins et al. 2010).

Sites affected by the Deepwater Horizon spill included locations along coastal Louisiana, with five BRPE collected from coastal Mississippi, where exposure to oil from the Deepwater Horizon spill was likely (Fig. 1). Reference sites for BLSK, BRPE, and GREG included various locations along coastal South Carolina and Georgia, USA where no recent oiling events had been recorded (Fig. 2). Because CLRA and SESP maintain small home ranges, reference sites for these two species included saline Juncus marshes, saline Spartina marshes, and brackish Phragmites marshes with no visible oil along coastal Louisiana, Mississippi, and and seaside sparrow. Because these two species maintain small home ranges, we classified Juncus marshes, saline Spartina marshes, and brackish Phragmites marshes with no known direct connectivity to the oil spill area as reference sites

Alabama (Fig. 1). We banded all birds with leg bands appropriate for each species and released them at the capture location after we completed oiling assessments and sample collection.

\section{Visible and UV oiling assessment}

We evaluated the majority of birds captured in both oiled and reference sites for evidence of visible oiling under natural lighting conditions, and assigned a visible oiling score of none ( $0 \%$ of plumage affected with visible oil), trace $(<5 \%$ plumage affected), light $(6-20 \%$ plumage affected) moderate (21-40\% plumage affected) or heavy ( $>40 \%$ plumage affected; see Supplementary Figs. 1, 2). We competed this examination under physical restraint appropriate for each species with wings in both extension and normal standing posture. We then placed each bird under an opaque canvas cover to block out natural light and exposed the plumage to UV light (Labino compact PH135 UV spotlight, Labino AB Solna, Sweden, $365 \mathrm{~nm}$ peak UV-A). We assigned a separate UV oiling score using the same five oil score categories. Thus, the same birds were categorized using two independent techniques (visible and UV oiling) to determine whether the use of a UV light source improved 
Fig. 2 Reference capture locations in South Carolina for American oystercatcher, black skimmer, brown pelican, and great egret

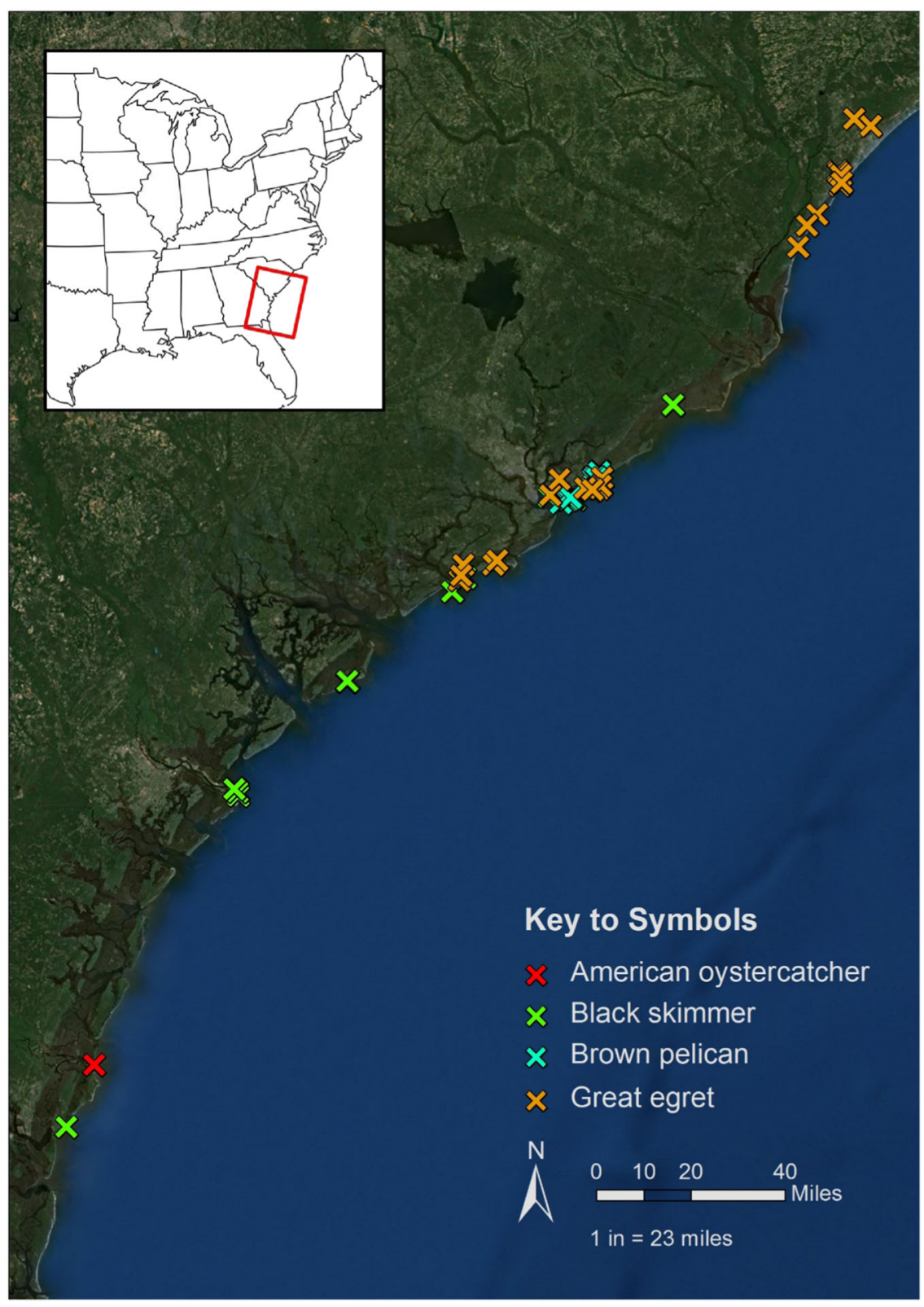

detection and severity of oiling (see example in Supplementary Fig. 3).

\section{Blood collection and sample handling}

We collected blood in a subset of individual BLSK, BRPE, and GREG from the medial metatarsal vein or superficial ulnar vein using a $21 \mathrm{G}$ or $23 \mathrm{G}$ butterfly catheter and lithium heparin and ethylenediaminetetraacetic acid (EDTA) vacutainers. These three species were selected for hematological analyses due to ease of blood collection and their relatively large body size. Immediately following collection, we filled two heparinized hematocrit tubes for packed cell volume (PCV) analysis. At this time, we also prepared new methylene blue-stained blood smears to quantify Heinz bodies and reticulocytes as described below. We placed remaining blood samples on ice and transferred them to the field laboratory. Once in the field laboratory, we prepared two additional EDTA-treated blood smears for complete blood cell analysis using a standard two-slide technique (Aird 2010).

\section{Hematologic parameters}

The hematological assessment methods and results, including our new methylene blue staining technique as well as reticulocyte and Heinz body identification, have been described in detail previously (Fallon et al. 2018). For 
BLSK, BRPE, and GREG, we prepared new methylene blue-stained blood smears in the field after incubating for $20 \mathrm{~min}$ (Fallon et al. 2013). We evaluated 1000 erythrocytes under 1000X light microscopy, counting the number of cells affected by Heinz bodies as well as the number of reticulocytes (Johns et al. 2008). The individual performing these analyses (JAF) was blinded to oiling status, capture location, and results of other analyses.

We determined PCV and hemoglobin (Hb) from heparinized samples within $12 \mathrm{~h}$ of collection. Packed cell volume (\%) was calculated using a standard hematocrit reader following centrifugation at $11,865 \times g$ for $5 \mathrm{~min}$. Total $\mathrm{Hb}(\mathrm{g} / \mathrm{dl})$ was quantified using a Hemocue $\mathrm{Hb}$ Analyzer Hb201 (Velguth et al. 2010). Red blood cell count (RBC, cells $/ \mathrm{mm}^{3}$ ) was estimated via standard manual methodology using a hemocytometer at a commercial laboratory (Avian and Exotics Clinical Pathology Laboratory, Wilmington, OH, USA) (Campbell 1995). Individuals performing these analyses were blinded to oiling status, capture location, and results of other analyses. Hematological results of these parameters in birds from reference sites and birds with visible oiling were first reported in Fallon et al. (2018), but are reanalyzed here in relation to the current UV oiling assessment.

\section{Statistical analyses}

We used SAS software (version 9.3 SAS Institute Inc., Cary, NC, USA) for all analyses. Where appropriate, we evaluated normality and homogeneity of variance using Shapiro-Wilk and Levene's tests, respectively. We used univariate statistical tests for physiological variable analyses, as this dataset contained missing values for one or more values in several birds (for more details, see Fallon et al. 2018). To account for the lack of independence of physiological responses compared in our univariate models, we applied a conservative $\alpha \leq 0.01$ to assess statistical significance in these models, while also noting cases where $\alpha$ $>0.01$ and $\alpha \leq 0.05$.

To determine the utility of UV light assessment as a tool to identify birds with small amounts of oil on the plumage that would otherwise be missed by visual oiling assessment, we used McNemar's exact test to compare the number of birds with visible oil to the number of birds with UV oiling from areas affected by the Deepwater Horizon spill within each species. Additionally, we calculated the number of birds that increased one or more category in oiling severity under the application of UV light (e.g., a bird that was categorized as light oiling under visual assessment appeared as moderate oiling under UV assessment) and compared the effect size of this change in severity using Cliff's delta (Cliff 1993, Romano et al. 2006, Macbeth et al. 2011). Cliff's delta is a measure of the degree of overlap between two populations, and ranges from -1 to +1 , with \pm 0.147 representing a small effect (percent of non-overlap is $14.7 \%$ ), \pm 0.33 representing a moderate effect (percent of non-overlap is $33 \%$ ), and $\geq \pm 0.474$ representing a large effect (percent of non-overlap is $47.4 \%$ (Cohen 1988).

To determine whether UV oiling assessment improved detection of birds experiencing adverse clinical signs compared to those detected through visual assessment alone, we first determined the effects of UV-detectable oiling on Heinz body formation, reticulocytes, PCV, $\mathrm{Hb}$, and RBC using Kruskal-Wallis tests for each species with subsequent post-hoc analysis (SAS Multtest procedure, Sas Institute Inc 2011). Additionally, we used Mann-Whitney tests to compare physiologic parameters (Heinz bodies, reticulocytes, $\mathrm{PCV}$, and $\mathrm{Hb}$ ) from birds with visible oiling to the subset of birds that had no evidence of visible oiling but tested positive for oiling under UV light. Because we had physiological data on a limited number of birds with UV oil but no visible oil, we pooled species for this analysis (Heinz bodies: BLSK $n=18$, BRPE $n=8$, GREG $n=5$ [ $n=31$ total]; reticulocytes: BLSK $n=18$, BRPE $n=8$, GREG $n=5,[n=31$ total]; PCV: BLSK $n=19$, BRPE $n=8$, GREG $n=7,[n=34$ total $]$; Hb: BLSK $n=11$, BRPE $n=6$, GREG $n=7,[n=24$ total $]$ ).

\section{Results}

\section{UV oiling assessment}

From our sample of 705 birds from areas impacted by the Deepwater Horizon spill, we identified 138 birds with evidence of visible oiling. However, the number of oiled birds from the same sample population increased by 259 individuals to 397 birds once we viewed them under UV light. Therefore, use of UV light increased the overall percentage of oiled birds in our sample population from 19.6 to $56.3 \%$ (Table 1, Fig. 3). Importantly, improved detection with the aid of a UV light occurred in all five species (Table 1,

Table 1 Number of individual black skimmer (BLSK), brown pelican (BRPE), clapper rail (CLRA), great egret (GREG), and seaside sparrow (SESP) from areas affected by the Deepwater Horizon oil spill with McNemar's test comparing visible oiling and UV fluorescence (*statistical significance)

\begin{tabular}{lcccrr}
\hline & Total $(N)$ & Visible oil & UV oil & \multicolumn{1}{c}{$\mathrm{Chi}^{2}$} & $p$ value \\
\hline BLSK & 120 & 47 & 92 & 45.00 & $<0.001^{*}$ \\
BRPE & 66 & 21 & 35 & 14.00 & $<0.001^{*}$ \\
CLRA & 100 & 14 & 82 & 65.06 & $<0.001^{*}$ \\
GREG & 54 & 38 & 46 & 8.00 & $0.005^{*}$ \\
SESP & 365 & 18 & 142 & 142.00 & $0.001^{*}$ \\
Total & 705 & 138 & 397 & & \\
\hline
\end{tabular}




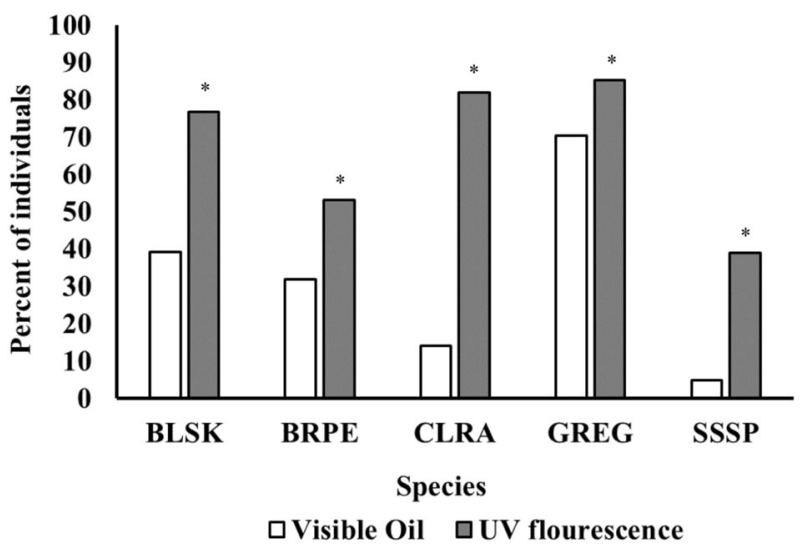

Fig. 3 Percent of black skimmer (BLSK), brown pelican (BRPE), clapper rail (CLRA), great egret (GREG), and seaside sparrow (SESP) in areas of potential impact from the Deepwater Horizon oil spill with visible oiling and oil detected under UV fluorescence. Asterisks indicate statistically significant difference $(p<0.05)$ between visible and UV detection techniques

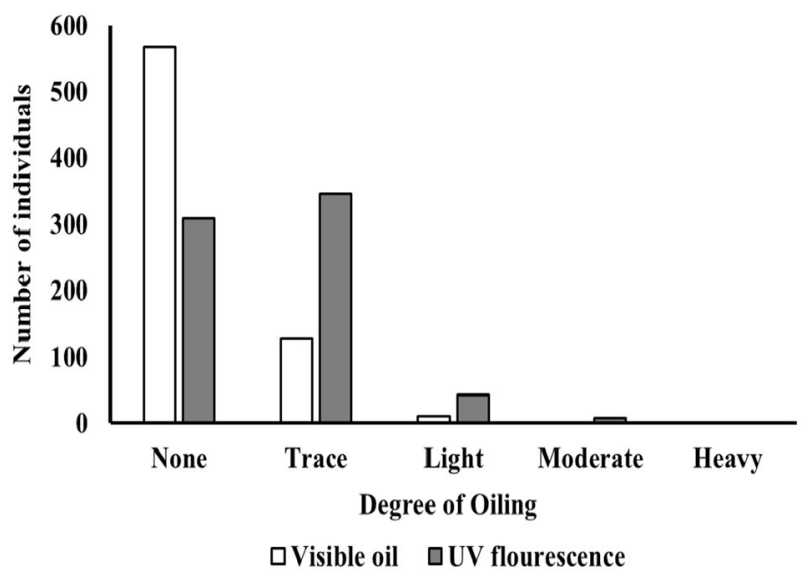

Fig. 4 Severity of visible oiling (none is $0 \%$ of plumage affected with UV oiling, trace $<5 \%$ plumage affected, light $6-20 \%$ plumage affected, moderate $21-40 \%$ plumage affected or heavy $>40 \%$ plumage affected) and oil detected under ultraviolet fluorescence in birds from areas affected by the Deepwater Horizon spill

Fig. 3). Additionally, we found evidence that the qualitative categorization of oiling severity increased when we evaluated birds under UV light; $40 \%$ of birds increased by at least one category (e.g., an increase from lightly to moderately oiled) after using UV compared to a standard visual exam (Fig. 4). Cliff's delta analysis revealed a moderate effect size on oiling severity with UV evaluation (delta $=$ $0.288)$. No BLSK $(n=87)$, BRPE $(n=39)$, or SESP $(n=$ 55 ) from reference locations were found to have oil on their plumage either by visual or UV assessment. We found no CPRL $(n=30)$ from reference sites with oil on standard visual assessment, but one individual was found to have trace amounts under UV assessment. In contrast, of 47 GREG from reference sites, 7 individuals had evidence of trace visible oil and 27 had trace or light UV oil.

\section{Physiological correlates of UV oiling}

The physiological responses associated with visible oiling were originally reported elsewhere (Fallon et al. 2018). Here, we focus on comparing the physiological responses detectable based on the two oiling assesment protocols. We found significantly more Heinz bodies and reticulocytes in BLSK, BRPE, and GREG with UV oiling compared to reference populations (Table 2). Additionally, we found significantly lower PCV and $\mathrm{Hb}$ in BRPE and GREG, as well as decreased RBC in GREG with UV oiling compared to reference populations (Table 2). Based on visual comparison of statistical outcomes of our previous study and the current study, we found that the effect of oiling on Heinz body formation, reticulocytes, $\mathrm{PCV}, \mathrm{Hb}$, and $\mathrm{RBC}$ counts was similar for both visual (data from Fallon et al. 2018) and UV assessment techniques (Table 3). Additionally, we found no significant difference between the mean number of Heinz bodies, reticulocytes, PCV, or $\mathrm{Hb}$ between birds that had only UV oiling and birds with oil apparent on both visual and UV oiling assessment (Table 4).

\section{Discussion}

It is important to understand the extent of exposure and injury to birds and other wildlife during oil spill events to develop an accurate damage assessment. While there were thousands of dead birds found in the weeks following the Deepwater Horizon spill, there were many more that were likely exposed to oil but did not immediately succumb (Peterson et al. 2003; USFWS 2011). We hypothesized that the use of hand-held UV lights could enhance the sensitivity of visible oiling assessments, because even trace amounts of oil have been shown to fluoresce (Chase et al. 2005). To test this, we evaluated 705 individuals from sites affected by the Deepwater Horizon oil spill with both visual and UV assessment. Ultraviolet assessment identified oiling on 259 individual birds (a 97\% increase in detection) that appeared to be oil-free on initial visual examination. Ultraviolet assessment resulted in a significant increase in the number of individuals determined to be oiled in all species, although this effect was least pronounced in GREG (Table 1, Fig. 3). Adult GREG have exclusively white plumage, which likely makes even trace amounts of oil more apparent on visual exam. Additionally, we found that UV assessment revealed that birds had more extensive exposure than was apparent on visual assessment, with $40 \%$ of birds increasing by at least one category of oiling severity after application of the UV light (Fig. 4). Cliff's delta analysis confirmed that this effect size was statistically significant. Together, these findings suggest that UV assessment can more accurately determine the number and severity of birds exposed to oil 


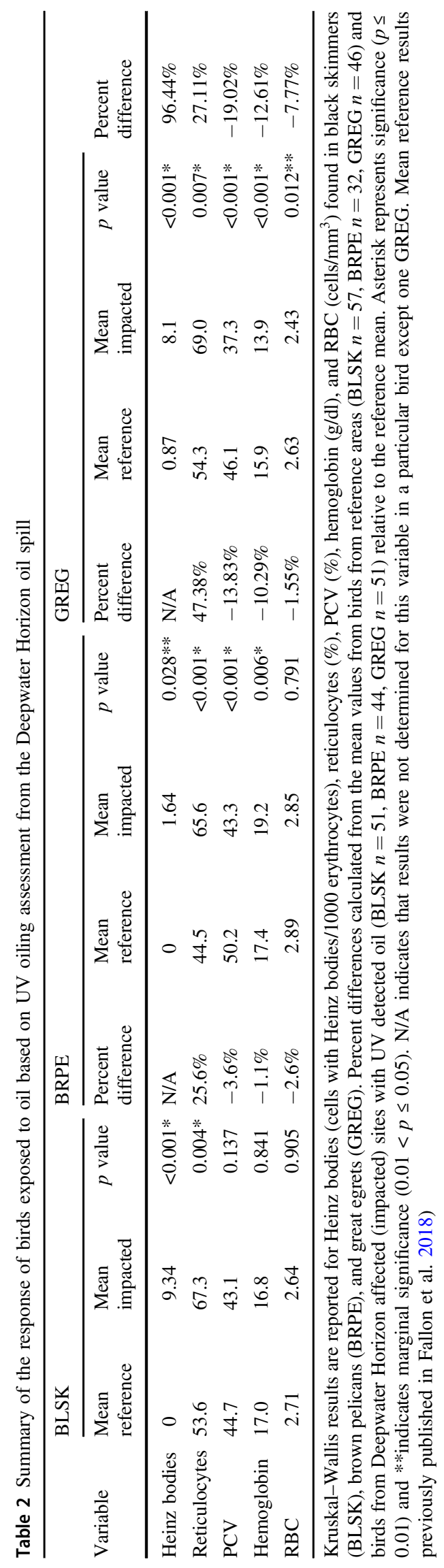

during spill events compared to visual assessment without the aid of UV light.

We found that UV-oiled birds were experiencing adverse effects similar to those we had observed in our prior visual assessment (Fallon et al. 2018). Birds with small amounts of oil on their plumage as determined by UV evaluation had hematological changes consistent with oxidative injury to red blood cells (Tables 2, 3). The presence of Heinz bodies combined with increased reticulocytes found in oiled BLSK, BRPE, and GREG with UV oiling suggests that this method can be used to detect birds with modest oiling that may be experiencing sublethal physiological injury. Additionally, BRPE and GREG from impacted sites had decreased PCV and $\mathrm{Hb}$. These three features-presence of Heinz bodies, decreased PCV or $\mathrm{Hb}$, and increased reticulocytes-are indicative of oxidative injury, anemia, and a physiological regenerative response. This physiologic cascade decreases oxygen availability to tissues (Latimer et al. 2003) which can induce muscle fatigue, lethargy, decreased energy availability for metabolic processes, and adversely affect reproduction (Butler et al. 1986; Piersma et al. 1996; Walton et al. 1997; Ots et al. 1998; Hylton et al. 2006). These physiological changes have implications for survival and fitness, suggesting that sublethal physiological injury associated with modest oil exposure may have important negative long-term repercussions for individuals. Although there is no clearly established threshold for what degree of reduced erythrocyte volume leads to decreased survival, anemia in oiled birds at admission to rehabilitation facilities is correlated with higher mortality rates (Duerr et al. 2016). Our results suggest that UV assessments can be useful in identifying birds with very small amounts of oil that also have experienced adverse effects, and that these hematological changes mirror those found with visible oiling (Fallon et al. 2018).

Although all BLSK, BRPE, and SESP and all but one CPRL from reference sites had no evidence of visual or UV oil on their plumage, GREG appeared to be at increased risk of oil exposure in our reference sites. Of 47 GREG from reference sites evaluated by both visual and UV assessment, 7 birds (15\%) had trace visual oiling and $27(57 \%)$ had trace $(n=26)$ or light $(n=1)$ UV oiling. Of our study species, GREG are the only species with exclusively white plumage, which may make small amounts of oil more easily discernible. Additionally, this species is unique among those in this study, as it is a wading bird that spends a great deal of foraging time standing or slowly wading through water, and frequents man-made drainage ponds and pooled, standing water from residential, agricultural, or industrial run-off which may contain petroleum waste (Trail 2006; McCrimmon et al. 2011). Consistent with their exposure, this was the only species in which Heinz bodies were identified in the reference population. Our results suggest that further 
Table 3 Summary of results from Kruskal-Wallis analysis of oiled birds as determined by visual assessment under natural lighting conditions (data from Fallon et al. 2018) compared to reference populations and UVassisted assessment compared to reference populations

\begin{tabular}{llllll}
\hline & Heinz Bodies & Reticulocytes & PCV & Hb & RBC \\
\hline BLSK & & & & & \\
UV oiled & $<0.001$ & 0.004 & 0.137 & 0.841 & 0.905 \\
$\quad$ Visibly oiled & $<0.001$ & 0.004 & 0.164 & 0.876 & 0.613 \\
BRPE & & & & & \\
UV oiled & 0.028 & $<0.001$ & $<0.001$ & 0.006 & 0.791 \\
Visibly oiled & 0.024 & $<0.001$ & $<0.001$ & 0.002 & 0.561 \\
GREG & & & & & \\
UV oiled & $<0.001$ & 0.007 & $<0.001$ & $<0.001$ & 0.012 \\
Visibly oiled & 0.003 & 0.010 & $<0.001$ & $<0.001$ & 0.003 \\
\hline
\end{tabular}

Response variables were Heinz bodies (cells with Heinz bodies/1000 erythrocytes), reticulocytes (\%), packed cell volume (PCV, \%), hemoglobin ( $\mathrm{Hb}, \mathrm{g} / \mathrm{dl})$, and red blood cell count $\left(\mathrm{RBC}\right.$, cells $\left./ \mathrm{mm}^{3}\right)$ found in black skimmers (BLSK), brown pelicans (BRPE), and great egrets (GREG)
Table 4 Mann-Whitney comparison of mean number of Heinz bodies (number of cells/1000 erythrocytes), reticulocytes (\%), packed cell volume $(\mathrm{PCV}, \%)$, and hemoglobin $(\mathrm{g} / \mathrm{dl})$ between birds (pooled species including black skimmers, brown pelicans, and great egrets) that tested positive for oiling under both UV and natural (visible) light versus those that tested positive under UV light only from sites impacted by the Deepwater Horizon oil spill

\begin{tabular}{llrlrrrr}
\hline & \multicolumn{2}{l}{ Visible and UV oil } & & \multicolumn{2}{l}{ UV oil only } & \\
\cline { 2 - 3 } Variable & $n$ & mean $( \pm$ SE $)$ & & $n$ & mean $( \pm$ SE $)$ & & $p$ value \\
\hline Heinz bodies & 79 & $8.22(1.99)$ & 31 & $2.87(1.58)$ & 0.355 \\
Reticulocytes & 79 & $69.08(2.10)$ & & 31 & $64.84(3.09)$ & 0.597 \\
PCV & 78 & $40.40(0.57)$ & 34 & $40.24(0.94)$ & 0.730 \\
Hemoglobin & 73 & $14.88(0.38)$ & & 24 & $15.40(0.53)$ & 0.320 \\
\hline
\end{tabular}

investigation into the frequency of exposure to petroleum products in this species is warranted.

There are several limitations to consider when incorporating UV light assessment during oil spill events. First, the individual bird must be evaluated under minimal natural light, which is cumbersome with large birds. Second, although application of UV light increased the detection of oiled birds, the majority of birds that appeared to be oil-free on visual examination that were determined to be oiled under UV light application had only trace or light amounts of oil on their plumage (5-20\% of plumage affected). Because of this, the severity of hematologic changes in the UV-oiled population of birds was similar to that of visibly oiled birds (Table 3, Fig. 4). Thus, UV assessment proved useful for enhancing detection of birds exposed to oil, but did not increase detection of birds experiencing clinical signs of anemia compared to standard visual assessment. Finally, there is the possibility of false positive fluorescence with naturally occurring oils. Further work in an experimental setting may help determine the frequency of false positive results.

In summary, our results demonstrate that UV assessment can identify small amounts of oil present on birds that appear oil-free on visual exam. Additionally, UV light allowed detection of oiled feathers over a larger proportion of surface area on individuals than can be seen on visual exam. Therefore, UV assessment of individual birds could be considered as an additional tool following both large and small oil spill events to help formulate a more complete damage assessment. This technique may be most useful to categorize birds with trace oiling that would otherwise be missed on visual exam, particularly in birds with dark plumage. Further, UV-oiled birds exposed to the Deepwater Horizon spill had evidence of oxidative injury to erythrocytes, decreased numbers of erythrocytes in circulation, and evidence of an erythrocytic regenerative response, similar to birds with visible oiling. These changes are consistent with formation of Heinz bodies and oxidative hemolytic anemia, a pathological abnormality caused by exposure to oil.

Acknowledgements The authors thank Pete Tuttle and Michael Hooper, for scientific advising, technical support, and assistance during this study. We are indebted to the many dedicated people who assisted with the collection of the avian samples, including Lisa Eggert who helped coordinate the collection of the BLSK samples; Lucas Savoy who coordinated the collection of CLRA, Dr. Peter Frederick and Jason Fidorra who led the collection of the GREG samples; Mike Yates and Jim Dayton who coordinated sample collection from BRPE. Additionally, BLSK, BRPE, GREG samples were processed in BRI's field laboratory by a dedicated team who provided excellent assistance, including Dr. Michelle Walsh, Dr. Lee Friedman, Ruth Valentine, Judi Ellal, Michelle Brown, Alishia Zyer, Tim Watson, and Ken Weber. Jeff Walters, Eric Hallerman, and Todd Katzner provided helpful comments that improved the manuscript. Any use of trade, firm, or product names is for descriptive purposes only and does not imply endorsement by the U.S. Government.

\section{Compliance with ethical standards}

Conflict of interest The authors declare that they have no conflict of interest.

Ethical approval The procedures involving animals were conducted by Biodiversity Research Institute with approval from the U.S. Fish and 
Wildlife Service. All applicable international, national, and/or institutional guidelines for the care and use of animals were followed.

Publisher's note Springer Nature remains neutral with regard to jurisdictional claims in published maps and institutional affiliations.

\section{References}

Alonso-Alvarez C, Munilla I, López M, Velando A (2007) Sublethal toxicity of the Prestige oil spill on yellow-legged gulls. Environ Intern 33:773-781

Aird B (2010) Clinical and hematologic manifestations of anemia. In: Feldman BF, Zinkl JG, Jain NC (eds) Schalm's veterinary hematology, 5th edn. Blackwell Publishing Ltd, Ames, Iowa, USA, p 140-142

Brekke C, Solberg AHS (2005) Oil spill detection by satellite remote sensing. Proc Spie 95:1-13

Briggs KT, Yoshida SH, Gershwin ME (1996) The influence of petrochemicals and stress on the immune system of seabirds. Regul Toxicol Pharmacol 23:145-55

Burlamacchi P, Cecchi G, Mazzinghi P, Pantani L (1983) Performance evaluation of UV sources for lidar fluorosensing of oil films. Appl Opt 22:48-53

Butler RG, Peakall DB, Leighton FA, Borthwick J, Harmon RS (1986) Effects of crude oil exposure on standard metabolic rate of Leach's storm-petrel. Condor 88:248-249

Campbell TW (1995) Avian hematology and cytology. Iowa State University Press, Ames, Iowa, USA

Chase CR, Van Bibber S, Muniz TP (2005) Development of a noncontact oil spill detection system. Oceans 2:1352-1357

Cliff N (1993) Dominance statistics: ordinal analyses to answer ordinal questions. Psychol Bull 114:494-509

Cohen J (1988) Statistical power analysis for the behavioral sciences, 2nd edn. Hillsdate, New Jersey, USA

Colligan TH, LaManna JM (1993) Using ultraviolet light to investigate petroleum-contaminated soil. Remediat J 3:193-201

Crozier GE, Gawlik DE (2003) The use of decoys as a research tool for attracting wading birds. J Field Ornithol 74:53-58

Duerr RS, Ziccardi MH, Massey JG (2016) Mortality during treatment: factors affecting the survival of oiled, rehabilitated Common Murres (Uria aalge). J Wildl Dis 52:495-505

Eppley ZA, Rubega MA (1990) Indirect effects of an oil spill: reproductive failure in a population of South Polar skuas following the 'Bahia Paraiso' oil spill in Antarctica. Mar Ecol Prog Ser $67: 1-6$

Esler D, Schmutz JA, Jarvis RL, Mulcahy DM (2000) Winter survival of adult female harlequin ducks in relation to history of contamination by the Exxon Valdez oil spill J Wildl Manag 64:839-847

Fallon JA, Hopkins WA, Fox L (2013) A practical quantification method for Heinz bodies in birds applicable to rapid response field scenarios. Environ Toxicol Chem 32:401-405

Fallon JA, Smith EP, Schoch N, Paruk JD, Adams EA, Evers DC, Jodice PG, Perkins C, Schulte S, Hopkins WA (2018) Hematological indices of injury to lightly oiled birds from the Deepwater Horizon oil spill. Environ Toxicol Chem 37:451-461

Fingas M, Brown CE (2014) Review of oil spill remote sensing. Mar Pollut Bull 83:9-23

Fingas M, Brown CE (2013) Detection of oil in ice and snow. J Mar Sci Eng 1:10-20

Fingas M, Brown C (2000) A review of the status of advanced technologies for the detection of oil in and with ice. Spill Sci Technol Bull 6:295-302

Fingas MF, Brown CE (1997) Review of oil spill remote sensing. Spill Sci Technol Bull 4:199-208
Fry M, Lowenstine LJ (1985) Pathology of Common Murres and Cassin's Auklets exposed to oil. Arch Environ Contam Toxicol 14:725-737

Fry DM, Swenson J, Addiego LA, Grau CR, Kangt A (1986) Reduced reproduction of wedge tailed shearwaters exposed to weathered Santa Barbara crude oil. Arch Environ Contam Toxicol $15: 453-463$

Giese M, Goldsworthy SD, Gales R, Brothers N, Hamill J (2000) Effects of the Iron Baron oil spill on little penguins (Eudyptula minor): breeding success of rehabilitated oiled birds. Wildl Res 27:583-591

Gochfeld M, Burger J, Lefevre KL (2020) Black Skimmer (Rynchops niger), version 1.0. In Birds of the World (S. M. Billerman, Editor). Cornell Lab of Ornithology, Ithaca, NY, USA. https:// doi.org/10.2173/bow.blkski.01

Golet GH, Seiser PE, McGuire AD, Roby DD, Fischer JB, Kuletz KL, Irons DB, Dean TA, Jewett SC, Newman SH (2002) Long-term direct and indirect effects of the Exxon Valdez oil spill on pigeon guillemots in Prince William Sound, Alaska. Mar Ecol Prog Ser 241:287-304

Harr KE, Cunningham FL, Pritsos CA, Pritsos KL, Muthumalage T, Dorr BS, Horak KE, Hanson-Dorr KC, Dean KM, Cacela D, McFadden AK (2017) Weathered MC252 crude oil-induced anemia and abnormal erythroid morphology in double-crested cormorants (Phalacrocorax auritus) with light microscopic and ultrastructural description of Heinz bodies. Ecotox Environ Saf 146:29-39

Herring G, Gawlik DE, Beerens JM (2008) Evaluating two new methods for capturing large wetland birds. J Field Ornithol 79:102-110

Hylton RA, Frederick PC, De La Fuente TE, Spalding MG (2006) Effects of nestling health on postfledging survival of wood storks. Condor 108:97-106

Iverson SA, Esler D (2010) Harlequin Duck population injury and recovery dynamics following the 1989 Exxon Valdez oil spill. Ecol Appl 20:1993-2006

Jha MN, Levy J, Gao Y (2008) Advances in remote sensing for oil spill disaster management: state-of-the-art sensors technology for oil spill surveillance. Sensors 8:236-255

Johns JL, Shooshtari MP, Christopher MM (2008) Development of a technique for quantification of reticulocytes and assessment of erythrocyte regenerative capacity in birds. Am J Vet Res 89:1067-1072

Latimer KS, Mahaffey EA, Prasse KW (2003) Duncan and Prasse's veterinary laboratory medicine: clinical pathology, 4th edn. Blackwell Publishing, Ames, Iowa, USA

Leighton FA (1986) Clinical gross and histological findings in Herring Gulls and Atlantic Puffins that ingested Prudhoe Bay oil. Vet Pathol 23:254-263

Leighton FA (1995) The toxicity of petroleum oils to birds: an overview. In: Frink L, Weir KB, Smith C (eds) Wildlife and oil spills. Tri-state Bird Rescue and Research, Inc., Newark, Delaware, USA, p 10-22

Leighton FA, Lee YZ, Rahimtula AD, O’Brien PJ, Peakall DB (1985) Biochemical and functional disturbances in red blood cells of herring gulls ingesting Prudhoe Bay crude oil. Toxicol Appl Pharmacol 81:25-31

Leighton FA, Peakall DB, Butler RG (1983) Heinz-body hemolytic anemia from the ingestion of crude oil: a primary toxic effect in marine birds. Science 4599:871-873

Macbeth G, Razumiejczyk E, Ledesma RD (2011) Cliff's delta calculator: a non-parametric effect size program for two groups of observations. Univ Psychol 10:545-555

McCrimmon, DA, Ogden JC, Bancroft GT, Martínez-Vilalta A, Motis A, Kirwan GM, Boesman PFD (2020) Great Egret (Ardea alba), version 1.0. In Birds of the World (S. M. Billerman, Editor). 
Cornell Lab of Ornithology, Ithaca, NY, USA. https://doi.org/10. 2173/bow.greegr.01

Mills JA, Ryder JP (1979) Trap for capturing shore and seabirds. Bird Band 50:121-123

Munilla I, Arcos JM, Oro D, Álvarez D, Leyenda PM, Velando A (2011) Mass peak mortality of seabirds in the aftermath of the Prestige oil spill. Ecosphere 2:1-14

Ots I, Murumägi A, Horak P (1998) Haematological health state indices of reproducing great tits: methodology and sources of natural variation. Funct Ecol 12:700-707

Perkins M, King SL, Linscombe J (2010) Effectiveness of capture techniques for rails in emergent marsh and agricultural wetlands. Waterbirds 33:376-380

Peterson CH, Rice SD, Short JW, Esler D, Bodkin JL, Ballachey BE, Irons DB (2003) Long term ecosystem response to the Exxon Valdez oil spill. Science 302:2082-2086

Piatt JF, Lensink CJ, Butler W, Kendziorik M, Nysewander DR (1990) Immediate impact of the Exxon Valdez oil spill on marine birds. Auk 107:387-97

Piersma T, Everaarts TM, Jukema J (1996) Build-up of red blood cells in refueling bar-tailed godwits in relation to individual migratory quality Condor 98:363-370

Post W, Greenlaw JS (2020) Seaside Sparrow (Ammospiza maritima), version 1.0. In Birds of the World (P. G. Rodewald, Editor). Cornell Lab of Ornithology, Ithaca, NY, USA. https://doi.org/10. 2173/bow.seaspa.01

Romano J, Kromrey JD, Coraggio J, Skowronek J, Devine L (2006) Exploring methods for evaluating group differences on the NSSE and other surveys: are the t-test and Cohen's d indices the most appropriate choices? In: Proceedings of the Annual Meeting of the Southern Association for Institutional Research, Arlington, VA, USA, pp 14-17

Rush SA, Gaines KF, Eddleman WR, Conway CJ (2020) Clapper Rail (Rallus crepitans), version 1.0. In Birds of the World (P. G. Rodewald, Editor). Cornell Lab of Ornithology, Ithaca, NY, USA. https://doi.org/10.2173/bow.clarai11.01
SAS Institute Inc (2011) Base SAS 9.3 procedures guide. SAS Institute Inc, Cary, NC

Seiser PE, Duffy LK, McGuire AD, Roby DD, Golet GH, Litzow MA (2000) Comparison of pigeon guillemot, Cepphus columba, blood parameters from oiled and unoiled areas of Alaska eight years after the Exxon Valdez oil spill. Mar Pollut Bull 40:152-164

Shields M (2020) Brown Pelican (Pelecanus occidentalis), version 1.0. In Birds of the World (A. F. Poole, Editor). Cornell Lab of Ornithology, Ithaca, NY, USA. https://doi.org/10.2173/bow. brnpel.01

Trail PW (2006) Avian mortality at oil pits in the United States: a review of the problem and efforts for its solution. Environ Manag 38:532-544

Troisi GM, Borjesson L, Bexton S, Robinson I (2007) Biomarkers of polycyclic aromatic hydrocarbon (PAH)-associated hemolytic anemia in oiled wildlife. Environ Res 105:324-329

Trust KA, Esler D, Woodin BR, Stegeman JJ (2000) Cytochrome P450 1A induction in sea ducks inhabiting nearshore areas of Prince William Sound, Alaska. Mar Pollut Bull 40:397-403

[USFWS] US Fish and Wildlife Service (2011) Deepwater Horizon bird impact data from the DOI-ERDC NRDA Database 12 May 2011. http://www.fws.gov/home/dhoilspill/pdfs/Bird\%20Data\% 20Species\%20Spreadsheet\%2005122011.pdf. Accessed 4 Aug 2012

Vieira BP, Furness RW, Nager RG (2018) What do we know about Black Skimmers? review on its annual-cycle and life-history main events. Ardea 106:119-130

Velguth KE, Payton ME, Hoover JP (2010) Relationship of hemoglobin concentration to packed cell volume in avian blood samples. J Avian Med Surg 24:115-121

Yamato O, IKoto I, Maede Y (1996) Hemolytic anemia in wild seaducks caused by marine oil pollution. J Wildl Dis 32:381-384

Walton RM, Brown DE, Hamar DW, Meador VP, Horn JW, Thrall MA (1997) Mechanisms of echinocytosis induced by Crotalus atrox venom. Vet Pathol 34:442-449 